\title{
Methodological Considerations for Advancing Research on the Health and Wellbeing of Sexual and Gender Minority Youth
}

\author{
Sheree M. Schrager, PhD, MS, ${ }^{1,2}$ Riley J. Steiner, MPH, PhD, ${ }^{3}$ Alida M. Bouris, PhD, MSW, ${ }^{4,5}$ \\ Kathryn Macapagal, $\mathrm{PhD}$, ${ }^{6,7}$ and $\mathrm{C}$. Hendricks Brown, $\mathrm{PhD}^{6,7}$
}

\begin{abstract}
Continued research with sexual and gender minority (SGM) youth is essential both to understand health disparities and to develop interventions targeting those disparities, but conducting rigorous, ethical research with these populations remains a substantial challenge. In addition to considerations for research with adolescents in general, such as utilizing developmentally appropriate measures and obtaining parental permission, factors unique to SGM youth must be addressed at every step of the research process. Defining the study population is complex, as is recruiting a sample once it is defined. Measurement is another challenge, given the paucity of measures developed for or validated with SGM samples. Key constructs, such as sexual orientation, gender identity, and family acceptance, are not amenable to randomization and involving minor participants' parents poses ethical concerns given the precarious home and safety situations that can arise from employing typical study procedures with youth who have a stigmatized identity. In this article, we examine some of these unique methodological challenges. Informed by theoretical and empirical literature, practical experience, and an ongoing dialogue with SGM youth themselves, we present a guide to best practices for ethical, productive research with SGM youth. By discussing existing approaches to studying SGM youth and suggesting innovative ways to approach the questions that remain, we hope to assist the research community in addressing methodological gaps to advance research on SGM youth in relation to families and schools.
\end{abstract}

Keywords: adolescents, ethics, gender minority, research methodology, sexual minority, youth

\section{Introduction}

$\mathbf{I}$ N 2016, THE CEnTERS FOR Disease Control and Prevention (CDC) released the first national prevalence estimates of the health-related behaviors of U.S. high school students who identify as lesbian, gay, or bisexual or who report same-sex contact. ${ }^{1}$ These data, which documented significant disparities in health-related behaviors between sexual minority and heterosexual youth, align with decades of findings from state- and community-based studies. ${ }^{2-11}$ Research with transgender and gender-expansive/gender-nonconforming adolescents has revealed similar disparities. ${ }^{12-14}$ The inclusion of sexual identity and same-sex behavior measures in U.S. national surveillance systems, and efforts to do the same with gen- der identity measures, ${ }^{15}$ reflects growing attention to sexual and gender minority (SGM) youth in public health research and surveillance in the United States. Ideally, such efforts will yield robust data to inform policies and programs that mitigate the stark disparities that exist.

However, conducting health research with SGM youth, defined here as young people ages $12-18$ who report samesex sexual attraction, identity, or behavior, and/or a gender identity or expression that differs from their sex assigned at birth, poses some unique challenges and methodological concerns. In June 2017, the Northwestern Institute for Sexual and Gender Minority Health and Wellbeing (ISGMH) hosted a public symposium on the health of lesbian, gay, bisexual, transgender, and queer or questioning (LGBTQ) youth in

\footnotetext{
${ }^{1}$ Department of Research and Sponsored Programs, California State University, Northridge, Northridge, California.

${ }^{2}$ Suzanne Dworak-Peck School of Social Work, University of Southern California, Los Angeles, California.

${ }^{3}$ Division of Adolescent and School Health, Centers for Disease Control and Prevention, Atlanta, Georgia.

${ }^{4}$ School of Social Service Administration, University of Chicago, Chicago, Illinois.

${ }^{5}$ Chicago Center for HIV Elimination, University of Chicago, Chicago, Illinois.

${ }^{6}$ Feinberg School of Medicine, Northwestern University, Chicago, Illinois.

${ }^{7}$ Institute for Sexual and Gender Minority Health and Wellbeing, Northwestern University, Chicago, Illinois.
} 
the United States. The symposium, titled "The State of LGBTQ Youth Health and Wellbeing: Strengthening Schools and Families to Build Resilience," featured a keynote address from David Purcell, JD, PhD, Deputy Director for Behavioral and Social Science of the Division of HIV/AIDS Prevention at CDC, who provided an overview of the health of SGM youth. In addition, he discussed the importance of developing interventions to support the health of SGM youth and reviewed promising strategies at the school and family levels. Following Dr. Purcell's address, Guillermo Prado, PhD, Dorothy Espelage, PhD, and Brian Mustanski, $\mathrm{PhD}$, spoke about their respective programs of research on family-based interventions for heterosexual and SGM youth, bullying and violence among SGM youth, and parental influences on the health and wellbeing of SGM adolescents. ${ }^{16}$ The three speakers were followed by a panel of youth leaders from the Illinois Caucus for Adolescent Health, who responded to the four presentations and called for additional research on the lived experiences of SGM youth.

Following the symposium, ISGMH hosted a day-long expert consultation to characterize areas of strong and emerging scientific evidence, gaps in knowledge, and research priorities regarding the role of families of origin and schools in addressing substance use, mental health and suicide, sexually transmitted infections (STIs) and HIV, and violence among SGM youth in the United States. The meeting was held in partnership with the Center for Prevention Implementation Methodology, Advocates for Youth, and the AIDS Foundation of Chicago. It was attended by 40 participants from academia, federal government health agencies, youth serving organizations, advocacy organizations, foundations, and youth themselves. ${ }^{17}$ As part of the meeting, working groups were formed to address key gaps in the extant research on school and family influences and interventions related to the health of SGM youth, with a particular focus on the U.S. context. Writing groups were formed to disseminate working group findings, which were reviewed by working group members before submission for peer review.

This article summarizes cross-cutting findings from working group discussions about key methodological considerations relevant to advancing research related to SGM youth and schools and families. Specifically, we address the following: (1) population definition, sampling, and recruitment, (2) measurement and interpretation, (3) study design, and (4) ethical considerations, including the unique challenges of each domain, the resulting gaps in knowledge, and methodological recommendations to address these gaps. Where possible, we provide illustrative examples specific to families and schools, thus serving as a methodological companion piece to the articles by Newcomb et al. ${ }^{18}$ and Johns et al. ${ }^{19}$ in this issue.

\section{Population Definition, Sampling, and Recruitment}

\section{Population and sample definition}

Explicitly defining and disaggregating SGM populations is complex. ${ }^{20,21}$ Gender identity and expression, and sexual attraction, behavior, and identity all reflect developmental processes; thus, the extent to which young people identify or express their sexual identity, attractions, behaviors, and/or gender varies widely both between and within individuals. Furthermore, even when youth identify with specific terminology, these youth may be reticent to disclose their identities to researchers. Youth may also have same-sex partners and identify as heterosexual, or identify as gay or bisexual but only report opposite-sex partners. In addition, research has documented sexual fluidity, for example, changes in reports of sexual attraction, behavior, and identity over time, in both adolescents and adults. ${ }^{22}$ Complicating matters further, processes and outcomes associated with social or other external factors, such as violence and victimization, may be more heavily influenced by public perceptions or assumptions about a youth's SGM group membership - correct or not - than by the youth's own identity. ${ }^{23,24}$ Reflecting these complexities, researchers' definitions of which youth they consider to belong to a particular SGM population also vary; for sexual minority youth, inclusion can be based on sexual identity, attraction, and/or behavior, and for gender minority youth, gender identity and/or expression may be determining factors. Consistent with best practice recommendations, ${ }^{25}$ we encourage researchers to fully consider all dimensions of sexual orientation and gender identity when defining the population of interest.

When defining the populations of interest, there is also a strong need for greater attention to the diversity among and between SGM youth. ${ }^{26}$ Conceptually, researchers would benefit from taking an intersectional approach when defining populations to ensure that the multiple identities of SGM youth, which include but certainly extend beyond sexual orientation and gender identity, are considered appropriately. Doing so could help to address certain populations that have been understudied, such as lesbian and bisexual young women, ${ }^{20,27}$ transgender or gender-expansive individuals, ${ }^{15}$ and racial/ethnic minority youth. ${ }^{28}$ Numerous researchers have discussed the importance and complexities of conducting intersectional research with members of SGM populations (see Bowleg, ${ }^{29}$ Cole,${ }^{30}$ and Fish $^{31}$ for detailed discussions).

\section{Sampling and recruitment approaches}

Studies on SGM youth to date have largely utilized nonprobability samples, as it can be difficult to establish a sampling frame for what has been described as a "hidden" population. ${ }^{32,33}$ Although sufficient for addressing many research questions, this approach precludes robust generalizations of findings at a population level. A frequent critique of sampling from community venues, a common approach, is that SGM participants engaged in these communities are fundamentally different from those who are not similarly engaged. ${ }^{34}$ For example, such an approach may exclude youth from rural contexts, those who are not yet out, or those who are not well-connected due to homelessness or mental health issues. ${ }^{33}$ One option that is endorsed increasingly by researchers involves online sampling and recruitment, ${ }^{35}$ which offers a variety of known benefits and limitations. ${ }^{33,36,37}$ A 2015 report from the Pew Research Center showed that $92 \%$ of adolescents across all races, ethnicities, and income levels use the Internet daily, and $71 \%$ of teens report using multiple social media sites. ${ }^{38}$ Moreover, Internet use is higher among SGM adolescents, who use online resources and social media to search for SGM-specific resources and social support, compared with their non-SGM adolescent counterparts. ${ }^{39}$ 
As such, Internet-based sampling and recruitment methods that meet youth where they are already can be an efficient way to identify and enroll eligible participants. Online recruitment methods include free or paid advertising on popular social media sites (e.g., Facebook, Instagram, Tumblr, and Twitter) and online promotion through partner organizations working with SGM youth. ${ }^{37,40}$ However, the burden to exclude low-quality and fraudulent data is proportionally higher for Internet-based studies as well, ${ }^{41}$ and using published quality control methods specific to online samples is advised. $^{42-45}$ Additional care must be taken to ensure sufficient diversity given a tendency for online samples to be skewed toward non-Hispanic White individuals with higher levels of education. Whenever possible, population diversity should be taken into consideration throughout the recruitment process, as this attention is necessary to attain large enough subgroups to disaggregate between and within diverse members of SGM populations. Options include tailored and inclusive online advertisements to reach individuals with a variety of sociodemographic characteristics and social experiences, ${ }^{46}$ or combining in-person and online sampling and recruitment. ${ }^{47}$ Keeping abreast of the constantly changing and emerging online spaces frequented by SGM youth remains a notable challenge. ${ }^{48}$

Efforts to collect data on SGM youth from probability samples are increasing, and some population-based studies have assessed sexual orientation and/or gender identity in large-scale anonymous surveys. ${ }^{49,50}$ Given that sample sizes of SGM youth in broad population studies are often insufficient for complex analyses, including examination of subgroup differences, a promising approach is oversampling by intentionally including more SGM participants and using sample weights to account for them in analysis. ${ }^{32,51}$ In particular, school-based research represents a unique opportunity to reach and incorporate information on SGM youth as part of a data collection effort targeting a larger group of students. ${ }^{19}$ Another option is to conduct a census of adolescents as a way to include sufficient numbers of SGM youth. ${ }^{52}$

There are strategies for reducing sampling biases in nonprobability samples as well, such as time-space sampling, in which sampling times are randomly selected. ${ }^{53}$ Respondentdriven sampling (RDS) is another method that relies not on venues but on social networks. ${ }^{54}$ RDS has the potential to produce unbiased population estimates, although the assumptions for doing so may or may not be met with SGM youth. ${ }^{34}$ These approaches can also be combined with online sampling and recruitment to further increase a study's reach. ${ }^{35}$

\section{Including families and schools}

Finally, there is a dearth of research with other individuals known to influence the health and wellbeing of SGM youth, such as family members and school staff. ${ }^{55-57}$ To date, most research has assessed parent/adolescent relationships retrospectively or has focused on adolescents' reports of their family relationships. ${ }^{58-62}$ Few studies have successfully enrolled parent/adolescent dyads, ${ }^{63,64}$ and investigators have struggled to involve parents directly who are unaccepting of or have only recently learned of their child's SGM identity, parents of youth who are not out to their families, and other family members such as siblings or grandparents.

Although there is more research on SGM youth in schools, this body of literature may suffer from similar sampling biases. School-based research on SGM youth may be biased toward enrollment of participants who are out to their peers or willing to obtain their parents' permission, or be more likely to occur in schools with a supportive environment toward SGM youth. Given the challenge of recruiting along a continuum from rejecting to accepting, recruiting from more accepting environments may be the most feasible option for now and will at least provide some data as a starting point, particularly in conjunction with analytic approaches that examine the role of acceptance. Such participants may also be able to offer important insights about how to reach other family members or educators with differing levels of acceptance.

\section{Measurement and Interpretation}

\section{Measuring sexual orientation and gender identity}

Given the aforementioned complexity in defining sexual orientation and gender identity, measurement of these constructs is a notable challenge. Rapidly shifting terminology among youth ${ }^{48}$ may reflect anything from measurement error to regional language differences to a genuine shift in the underlying construct, for example, fluidity in self-ascribed identity over time. For these reasons, researchers may consider allowing youth to express their sexual and/or gender identity via an open-ended text box, and use closed-ended items to capture other salient aspects of these identities (e.g., romantic/sexual attraction and gender expression) necessary for eligibility verification or later quantitative analysis. This may be especially criticial in longitudinal studies, given the likelihood of identity to change over the span of adolescent development. ${ }^{22}$

For sexual orientation in particular, we concur with previously published recommendations to prioritize the measurement of attraction, deprioritize measurement of behavior (for sample definition purposes), and give special consideration to item placement and skip logic. ${ }^{25,65}$ Regardless of which items are chosen, investigators should be cognizant of the need to strike a balance between terminology that youth can understand and with which they are comfortable, and avoid overly clinical or dehumanizing language; for example, there are many reasons not to use the term "biological sex" when referring to sex assigned at birth. ${ }^{66,67}$ For gender in particular, many experts use the combination of sex assigned at birth and at least one indicator of current asserted gender, although the choice of items and response options can vary depending on whether the target sample will be drawn from a general youth population, members of diverse SGM youth populations, or a gender-expansive population specifically. ${ }^{68}$

Researchers are also advised to examine the rationale for selecting one measure of identity over another, particularly among closed-ended items. Identity labeling is often used in the service of broadly categorizing participants into groups to support later comparisons (e.g., gay vs. lesbian vs. bisexual participants). However, the assignment of individuals to these groups may introduce bias, particularly if there is an underlying conscious movement away from a given label. ${ }^{69,70}$ An overreliance on identity labeling may also lead to erroneous conclusions about identity-based group differences that are more appropriately attributable to externally perceived characteristics, such as gender expression. $^{24}$ Even when a more diverse sample of SGM 
youth is recruited, the tendency to combine SGM subgroups as a way to increase samples sizes has led to frequent analysis of sexual orientation and gender identity as a monolithic construct. Not only has this approach likely reinforced the broader conflation of sexual orientation and gender identity, it can also obscure known health risk disparities that vary between sexual minority and gender minority youth and among sexual minority subgroups. ${ }^{71}$ When examining social and behavioral health outcomes, in particular, we suggest including a measure or proxy for metaperception, that is, the respondent's beliefs about others' perceptions of the respondent, ${ }^{72}$ to aid in disentangling true identity-driven group differences from effects based on socially perceived or categorized group membership.

\section{Measuring outcomes}

To date, most studies that are inclusive of SGM youth have focused on indicators of health behaviors and associated morbidity and mortality among American youth, ${ }^{73,74}$ such as poor mental health; suicidal and nonsuicidal selfinjurious behaviors; sexual behaviors that contribute to unplanned pregnancies, STIs, and HIV; alcohol, tobacco, and other drug use; behaviors that contribute to unintentional injuries; unhealthy dietary behaviors; and inadequate physical activity. ${ }^{1,26}$ In addition, a large body of research has examined experiences with bullying, violence, and other forms of victimization. ${ }^{1,26}$ These studies have played a critical role in documenting the presence of health disparities between SGM and cisgender, heterosexual youth and between diverse subgroups of SGM young people, such as sexual minority and gender minority individuals. ${ }^{1,26}$ Although we see no reason to stop monitoring these outcomes, the field must expand its focus and measure additional outcomes, including targets that may only be salient to specific subgroups of SGM youth (e.g., gender-expansive youth), if we are to develop effective programs and policies that can improve the health and wellbeing of SGM youth.

Three interrelated outcomes that warrant additional broad focus are (1) psychological resilience, (2) coping and related processes, and (3) the social contexts in which SGM youth grow and develop. ${ }^{75}$ Most research has examined these domains as correlates or mediators of health and wellbeing, with significantly less attention given to each domain as an outcome that is itself shaped by larger social and contextual factors. A lack of conceptual and theoretical work in this area makes it difficult to identify the factors that promote healthy social environments for SGM young people. For example, in the family domain, parental rejection has emerged as a clear correlate of negative health outcomes for SGM youth. ${ }^{76}$ However, less research has conceptualized the underlying social and psychological factors (i.e., specific cognitive and emotional factors) that drive parental rejection. This kind of theorizing and associated measurement are necessary to identify the correlates of rejection that can be targeted in future intervention research. Finally, although longitudinal studies have shown evidence that health outcome disparities persist into young adulthood and may even worsen, ${ }^{77}$ research that captures the dynamic social developmental context has lagged far behind. In fact, despite the recognition that stigmatizing experiences can disrupt the achievement of developmental tasks during adolescence and contribute to negative outcomes, ${ }^{78}$ the first large study to comprehensively examine the relationship between social contexts and behavioral health outcomes longitudinally among SGM youth (MD012252) was only funded in 2017 and is still underway. Critical gaps remain in our understanding of resilience, coping, and social context across stages of SGM youth development.

\section{Overarching considerations for measure selection}

Across population characteristics and outcomes, the dearth of available research on representative samples of SGM youth broadly and disaggregated subgroups has resulted in the proliferation of unvalidated measures with poor psychometric performance, ${ }^{79}$ particularly related to victimization, homophobic attitudes, and other aspects of gender and sexual minority stress. ${ }^{80}$ Although some validated measures are emerging, ${ }^{81,82}$ we caution researchers that qualitative research, cognitive testing, and validity and reliability studies may still be required ${ }^{83}$ - especially when a measure is directly relevant to gender or sexual identity, as the terminology used in older measures may not be sufficiently sensitive or reflective of modern youth experience. ${ }^{48}$ Of course, measure selection for research with SGM youth should also be informed by measurement considerations relevant to the general population of adolescents, such as literacy, developmental appropriateness, and survey fatigue. ${ }^{84-87}$

\section{Study Design}

Despite the proliferation of research documenting disproportionate adverse health outcomes among SGM youth, there remain substantial gaps in our scientific knowledge of interventions to improve SGM youth health and wellbeing. For example, although considerable progress has been made in the development of biomedical and behavioral interventions for the prevention or treatment of HIV ${ }^{88,89}$ less is known about the benefit of such interventions for youth. ${ }^{90,91}$ The 2018 Food and Drug Administration approval for use of pre-exposure prophylaxis among adolescents at risk for HIV acquisition ${ }^{92}$ will hopefully spur additional research on implementation for SGM youth, which has specific challenges related to parental consent, confidentiality, and health privacy. ${ }^{93-95}$ More broadly, there is a need for a shift from such models of health disparity, where health imbalances and antecedent risk and protective factors are identified, to health equity and the identification of interventions to successfully overcome these disparities. The former studies require population-based epidemiologic and developmentally based cross-sectional or longitudinal designs, whereas the latter require rigorous intervention trials. We must examine the potential utility for SGM youth of available prevention interventions developed originally for a general population of adolescents, and we must also develop and evaluate new interventions using rigorous designs appropriate for use with SGM youth.

\section{Design considerations based on existing interventions}

Existing universal and targeted prevention interventions for a variety of physical and behavioral health outcomes can be evaluated to examine whether SGM youth benefit as much as, or less than, other youth when exposed to 
these interventions. Relatedly, we can examine whether general school- or community-based interventions targeting anti-homosexual and anti-transgender attitudes, bullying, and violence toward other stigmatized youth actually improve outcomes for SGM youth. We propose a design strategy for evaluating these interventions specifically for SGM populations, using suicide prevention as an illustrative example given the extremely high rate of suicide attempts among SGM high school youth compared with non-SGM youth. ${ }^{1,96}$

A first step would involve synthesizing individual-level data from published social and behavioral intervention trials that (1) target the outcome of interest (e.g., youth suicide), directly or indirectly by addressing known risk and/or protective factors (e.g., depression, anxiety, bullying, and alcohol or drug use); (2) measure behavioral outcomes (e.g., suiciderelated attempts and planning), and (3) document participants' sexual orientation or gender identity. For our suicide example, we know of 23 randomized trials that meet these criteria, including a total of 100,851 youth who were randomized to an active preventive intervention or control condition. ${ }^{97}$ Of these youth, more than 5000 could be classified as a member of an SGM population based on self-reported gender identity or sexual identity, attraction, or behavior.

By combining individual-level data from multiple trials such as these and using integrative data analysis approaches, ${ }^{97,98}$ it is possible to obtain sufficient statistical power to detect small to moderate intervention effects in SGM youth and contrast this with the impact on non-SGM youth using moderation analyses. To account for different ways that studies have chosen to measure outcomes of interest, ${ }^{98}$ we can standardize all trial measures against independently developed and prospectively validated scales or indicators. ${ }^{99}$ Although intensive, the strength of this design rests in the use of available data, the ability to make ready comparisons both between SGM and non-SGM youth and among distinct SGM subgroups, and the combination of trial data that by themselves have minimal power. Its weakness is the inability to address questions other than those from existing trials, which rarely engage the unique needs of SGM youth in the contexts of school, family, and community.

\section{Design considerations for new intervention studies}

Conducting research that considers the unique needs of SGM youth will require new intervention studies. Procedures for conducting traditional randomized trials of intervention efficacy or effectiveness are well described, ${ }^{100}$ but there are challenges in conducting such studies with SGM youth. One major challenge is that even implementing an SGMfocused intervention can increase the chance of unintended disclosure of the youth's identity or sexual behavior to someone close, such as a family member, counter to the youth's own wishes. For interventions that include parenting programs to support SGM youth, as well as school-based interventions that start by acknowledging youths' sexual orientation and gender identity, additional methods to minimize unintended disclosures may be needed. As many youth often reveal information regarding their gender identity or sexual attractions, behavior, or identity in the virtual world ${ }^{101}$ before disclosing to friends or families in person, ${ }^{102}$ and youth are often comfortable navigating the Internet to receive information and connect, it makes sense to consider de- signing and delivering interventions that make use of these potentially powerful technologies. ${ }^{103,104}$ The Keep It Up! Intervention, ${ }^{105}$ which was designed to help young men who have sex with men adopt safer sexual behaviors and form healthy relationships, is one example of an interactive e-health intervention that could serve as a model for the health and wellbeing needs of other SGM populations, including youth.

SGM-specific considerations for retention (or attrition) could also have important design implications, as youth in one arm of a trial may be more prone to withdrawing from the study for reasons related ${ }^{106}$ or unrelated ${ }^{46,107}$ to the intervention (e.g., structural barriers to continued participation). Although there is a strong tradition of randomized controlled trials relying only on intent-to-treat analysis for impact, in which all individuals who are randomized to a condition in the study are analyzed together regardless of how much of the assigned intervention they received, the impact of differential and informative dropout should be examined as well. ${ }^{108}$

An additional design challenge is linked directly to the difficulty in obtaining representative samples as described earlier in the article. For example, if only parents who are highly comfortable with their child's acknowledged sexual or gender identity agree to participate in a family intervention study, the inherent selection bias would make it inaccurate to infer a trial's findings to a broader group of families or the full population. However, some potential design approaches may be both ethical and appropriate to use. For example, if an intervention requires parental acceptance of a youth's identity, one could consider a design that deliberately enrolls families where the index youth varied in age and in the duration of parental acceptance. Analytic models then could be used to express the impact of the intervention against a comparison condition within age groups as a function of how long the parents had accepted the youth's identity. If there is a consistent effect regardless of how long parents had accepted the youth, it would lend weight toward the hypothesis that parental acceptance is not a prerequisite for intervention success. A similar analysis examining intervention effect by degree of acceptance could be undertaken if parental acceptance were measured with sufficient variability.

\section{Ethical Considerations}

Up to this point, we have focused on the practical need to adjust study approaches to accommodate the needs of SGM youth. However, the literature on ethical issues in research with SGM adolescents also has underscored the need to increase representation of SGM youth in research that has the potential to improve their health, recognize that SGM youth have the ability to make autonomous decisions about research participation, and reduce their risk of harm throughout the research process. ${ }^{109-113}$ We describe several important ethical considerations when conducting research with SGM youth and their families.

General research with minors, including adolescents, typically requires the consent of a parent or legal guardian for youth to participate in research activities. However, such parental consent to participate in an SGM-focused study may require youth to disclose their SGM identity to their parents or guardians, which places them at risk of experiencing victimization, abuse, and rejection. ${ }^{61,114}$ Empirical research has 
found that requiring parental consent reduces SGM youths' willingness to participate in research studies, biasing samples toward youth who are out, have supportive relationships with their families, or do not engage in high-risk behaviors, ${ }^{115-117}$ threatening the validity of research findings. ${ }^{118}$

SGM health researchers commonly address these concerns by requesting waivers of parental permission for studies that pose no more than a minimal risk of harm. Some studies have found that parents are supportive of permission waivers for research with SGM youth. ${ }^{119,120}$ Such waivers may be especially useful for school-based research studies for which special attention is needed, given that school staff records are accessible to parents and could result in inadvertent disclosure of a student's SGM identity. ${ }^{113}$ It is thus critical to ensure that documentation of parental consent is maintained by an external research team rather than school staff. As different institutional review boards (IRBs) may have different stances on granting permission waivers, investigators may wish to refer to published case examples and toolkits to navigate this process. ${ }^{109,110,121}$ For multisite studies, reliance on a single IRB with experience in protection of SGM youth subjects may also be an option. ${ }^{122}$

Privacy and confidentiality breaches are another concern that may affect SGM samples disproportionately. Health and risk information are common areas of study with SGM youth that can trigger mandated reporting to service providers (e.g., suicidality), welfare agencies (e.g., child abuse), or the health department (e.g., new diagnosis of some STIs). During the consent process, being explicit about situations that necessitate breaks in confidentiality, and to whom their identifying information may be disclosed, can aid youth in making the best decision for themselves about participation. Finally, seemingly benign aspects of a study may run the risk of exposing youth's SGM identity to others. For example, advertisements that use terms or imagery reflective of SGM communities may be seen by peers or family, and studies that occur in physical locations associated with SGM communities may "out" a prospective participant unintentionally. Thus, investigators should carefully consider the extent to which their research studies warrant discretion, depending on the nature and context of the study.

Furthermore, conditions at the start of the study that enabled youth to feel comfortable enrolling could change over the course of participation, particularly in longitudinal studies and intervention trials. Youth who may be open to broader disclosure of their SGM identity at one point in time may decide that it is no longer appropriate or safe to continue sharing with family members, school staff, or other acquaintances. Because personal and social circumstances change as a youth matures both physically and emotionally, a design protocol could include structured times for the youth to review their decision to continue participation. Trials in areas of health other than those specifically pertinent to SGM have incorporated special consideration for changing assent/consent, and researchers testing interventions for SGM youth may consider following suit in adapting protocols to protect youth who express concerns about continued participation. ${ }^{123}$

\section{Conclusions}

Research on the health of SGM youth in the United States has grown considerably in recent years. Despite this growth, there remain a number of structural factors that limit or inhibit the collection of vital information about the health of SGM populations (e.g., federal funding priorities and inclusive versus discriminatory policies), slowing the rate of scientific advancement. ${ }^{124,125}$ In this article, we make specific methodological recommendations for improving the science on the health of SGM youth with illustrative examples from the school and family contexts of SGM young people in the United States. Future work should consider research from other contexts, both similar to and distinct from the United States, to strengthen the field's understanding of how to improve the health of SGM youth around the world.

Ultimately, addressing existing gaps will necessitate working collaboratively with youth, schools, and families to craft adequate protections that minimize the potential harms and maximize the possible benefits associated with participating in research. This work will require considerable time and resources but is necessary if we are to address sampling biases and measurement issues, and recruit and retain representative samples of SGM youth over time-all of which are necessary to develop feasible, acceptable, and effective interventions that can improve the health of SGM youth. As this work progresses, synthesis studies offer one avenue through which to strengthen the extant knowledge about SGM youth. However, interventions to support the health and wellbeing of SGM youth are needed greatly, in the United States and beyond, as youth who identify as gender and/or sexual minorities report greater exposure to risk factors, less access to protective factors, and poorer health-related behaviors and health outcomes than do their cisgender and/or heterosexual peers. ${ }^{1-14}$ We strongly encourage researchers to address the methodological issues identified in this article in their work with SGM youth, to advance prevention science, and ultimately to help address health disparities that compromise the health of SGM youth in adolescence and beyond.

\section{Acknowledgments}

The authors would like to thank the researchers, practitioners, and community members who participated in the 2017 State of LGBTQ Youth Health and Wellbeing Symposium at Northwestern University. Their contributions were essential to the development of this article. We would also like to acknowledge the substantial efforts of Brian Mustanski and Francesca Gaiba in organizing the symposium, supporting the development of this article, and lending their expertise throughout the process, as well as Krystal Baker and Gates Crisler for their help in preparing the initial manuscript draft. The symposium and consultation were supported by the Northwestern University Institute for Sexual and Gender Minority Health and Wellbeing and the National Institute on Drug Abuse (P30DA027828-07S1). Portions of this article were supported by funding from the National Institute of Mental Health (R01MH117598) and the National Institute on Minority Health and Health Disparities (R01MD012252-01 and R01MD009561).

\section{Disclaimer}

The content in this article is solely the responsibility of the authors and does not necessarily represent the official views of the National Institutes of Health or the Centers for Disease Control and Prevention. 


\section{Author Disclosure Statement}

No competing financial interests exist.

\section{References}

1. Kann L, Olsen EO, McManus T, et al.: Sexual identity, sex of sexual contacts, and health-related behaviors among students in grades 9-12 - United States and selected sites, 2015. MMWR Surveill Summ 2016;65:1-202.

2. Remafedi G, Resnick M, Blum R, Harris L: Demography of sexual orientation in adolescents. Pediatrics 1992;89: 714-721.

3. Saewyc EM, Skay CL, Bearinger LH, et al.: Sexual orientation, sexual behaviors, and pregnancy among American Indian adolescents. J Adolesc Health 1998; 23:238-247.

4. Reis B, Saewyc EM: Eighty-three thousand youth: Selected findings of eight population-based studies. Seattle, WA: Safe Schools Coalition of Washington, 1999. Available at www.safeschoolscoalition.org/83000youth .pdf Accessed April 7, 2019.

5. Rotheram-Borus MJ, Marelich W, Srinivasan S: HIV risk among homosexual, bisexual, and heterosexual male and female youths. Arch Sex Behav 1999;28:159-177.

6. Robin L, Brener ND, Donahue SF, et al.: Associations between health risk behaviors and opposite-, same-, and both-sex sexual partners in representative samples of Vermont and Massachusetts high school students. Arch Pediatr Adolesc Med 2002;156:349-355.

7. Everett BG, Schnarrs PW, Rosario M, et al.: Sexual orientation disparities in sexually transmitted infection risk behaviors and risk determinants among sexually active adolescent males: Results from a school-based sample. Am J Public Health 2014;104:1107-1112.

8. Burton CM, Marshal MP, Chisolm DJ, et al.: Sexual minority-related victimization as a mediator of mental health disparities in sexual minority youth: A longitudinal analysis. J Youth Adolesc 2013;42:394-402.

9. Rosario M, Corliss HL, Everett BG, et al.: Sexual orientation disparities in cancer-related risk behaviors of tobacco, alcohol, sexual behaviors, and diet and physical activity: Pooled Youth Risk Behavior Surveys. Am J Public Health 2014; 104:245-254.

10. Austin SB, Nelson LA, Birkett MA, et al.: Eating disorder symptoms and obesity at the intersections of gender, ethnicity, and sexual orientation in US high school students. Am J Public Health 2013;103:e16-e22.

11. Hanson B: Invisible Youth: The health of lesbian, gay, bisexual, and questioning adolescents in Minnesota: A report. Minneapolis, MN: Rainbow Health Initiative, 2015. Available at www.justushealth.mn/sites/default/files/ inline-files/Oct_23_MSS_Report.pdf Accessed February $18,2019$.

12. Reisner SL, Vetters R, Leclerc M, et al.: Mental health of transgender youth in care at an adolescent urban community health center: A matched retrospective cohort study. J Adolesc Health 2015;56:274-279.

13. Reisner SL, Greytak EA, Parsons JT, Ybarra ML: Gender minority social stress in adolescence: Disparities in adolescent bullying and substance use by gender identity. J Sex Res 2015;52:243-256.

14. Day JK, Fish JN, Perez-Brumer A, et al.: Transgender youth substance use disparities: Results from a populationbased sample. J Adolesc Health 2017;61:729-735.
15. Conron KJ, Landers SJ, Reisner SL, Sell RL: Sex and gender in the US health surveillance system: A call to action. Am J Public Health 2014;104:970-976.

16. Institute for Sexual and Gender Minority Health and Wellbeing. ISGMH Hosts Second Annual Symposium on June 29, 2017. July 17, 2017. Available at https://isgmh .northwestern.edu/2017/07/17/isgmh-hosts-second-annualsymposium-the-state-of-lgbtq-youth-health-and-wellbeingstrengthening-schools-and-families-to-build-resilience Accessed January 31, 2019.

17. Institute for Sexual and Gender Minority Health and Wellbeing. The State of LGBTQ Youth Health and Wellbeing: Strengthening Schools and Families to Build Resilience Working Group Meeting. Available at https://cpb-us-e1 .wpmucdn.com/sites.northwestern.edu/dist/3/817/files/2017/ 07/Working-Group-Historical-Record-2dytc7x.pdf Accessed January 31, 2019.

18. Newcomb ME, LaSala MC, Bouris A, et al.: The influence of families on LGBTQ youth health: A call to action for innovation in research and intervention development. LGBT Health 2019;6:139-145.

19. Johns MM, Poteat VP, Horn SS, Kosciw J: Strengthening our schools to promote resilience and health among LGBTQ youth: Emerging evidence and research priorities from The State of LGBTQ Youth Health and Wellbeing Symposium. LGBT Health 2019;6:146-155.

20. Arbeit MR, Fisher CB, Macapagal K, Mustanski B: Bisexual invisibility and the sexual health needs of adolescent girls. LGBT Health 2016;3:342-349.

21. Savin-Williams RC: A critique of research on sexualminority youths. J Adolesc 2001;24:5-13.

22. Diamond LM: Sexual fluidity in male and females. Curr Sex Health Rep 2016;8:249-256.

23. Waldner LK, Berg J: Explaining antigay violence using target congruence: An application of revised routine activities theory. Violence Vict 2008;23:267-287.

24. Lehavot K, Lambert AJ: Toward a greater understanding of antigay prejudice: On the role of sexual orientation and gender role violation. Basic Appl Soc Psych 2007;29:279-292.

25. Sexual Minority Assessment Research Team (SMART): Best Practices for Asking Questions about Sexual Orientation on Surveys. Los Angeles, CA: The Williams Institute, UCLA, 2009.

26. Institute of Medicine (US) Committee on Lesbian, Gay, Bisexual, and Transgender Health Issues and Research Gaps and Opportunities: The Health of Lesbian, Gay, Bisexual, and Transgender People: Building a Foundation for Better Understanding. Washington, DC: National Academies Press (US), 2011.

27. Eliason MJ: Lesbian and bisexual women's health is critically understudied. BJOG 2017;124:403.

28. Mustanski BS, Newcomb ME, Du Bois SN, et al.: HIV in young men who have sex with men: A review of epidemiology, risk and protective factors, and interventions. J Sex Res 2011;48:218-253.

29. Bowleg L: When Black + lesbian + woman $\neq$ Black lesbian woman: The methodological challenges of qualitative and quantitative intersectionality research. Sex Roles 2008;59:312-325.

30. Cole ER: Intersectionality and research in psychology. Am Psychol 2009;64:170-180.

31. Fish J: Navigating queer street: Researching the intersections of lesbian, gay, bisexual and trans (LGBT) identities in health research. Soc Res Online 2008;13:1-12. 
32. Anderssen N, Malterud K: Oversampling as a methodological strategy for the study of self-reported health among lesbian, gay and bisexual populations. Scand J Public Health 2017;45:637-646.

33. McDermott E, Roen K: Youth on the virtual edge: Researching marginalized sexualities and genders online. Qual Health Res 2012;22:560-570.

34. Meyer IH, Wilson PA: Sampling lesbian, gay, and bisexual populations. J Couns Psychol 2009;56:23-31.

35. Lachowsky NJ, Lal A, Forrest JI, et al.: Including onlinerecruited seeds: A respondent-driven sample of men who have sex with men. J Med Internet Res 2016;18:e51.

36. Riggle ED, Rostosky SS, Reedy CS: Online surveys for BGLT research: Issues and techniques. J Homosex 2005; 49:1-21.

37. Prescott TL, Phillips II G, DuBois LZ, et al.: Reaching adolescent gay, bisexual, and queer men online: Development and refinement of a national recruitment strategy. J Med Internet Res 2016;18:e200.

38. Lenhart A: Teens, Social Media \& Technology Overview 2015. Washington, DC: Pew Research Center, 2015.

39. GLSEN, CiPHR, \& CCRC: Out Online: The Experiences of Lesbian, Gay, Bisexual and Transgender Youth on the Internet. New York, NY: GLSEN, 2013.

40. Allison S, Bauermeister JA, Bull S, et al.: The intersection of youth, technology, and new media with sexual health: Moving the research agenda forward. J Adolesc Health 2012;51:207-212.

41. Robinson-Cimpian JP: Inaccurate estimation of disparities due to mischievous responders: Several suggestions to assess conclusions. Educ Res 2014;43:171-185.

42. Aust F, Diedenhofen B, Ullrich S, Musch J: Seriousness checks are useful to improve data validity in online research. Behav Res Methods 2013;45:527-535.

43. Bauermeister J, Pingel E, Zimmerman M, et al.: Data quality in web-based HIV/AIDS research: Handling invalid and suspicious data. Field Methods 2012;24: 272-291.

44. Teitcher JE, Bockting WO, Bauermeister JA, et al.: Detecting, preventing, and responding to "fraudsters" in internet research: Ethics and tradeoffs. J Law Med Ethics 2015;43: 116-133.

45. Grey JA, Konstan J, Iantaffi A, et al.: An updated protocol to detect invalid entries in an online survey of men who have sex with men (MSM): How do valid and invalid submissions compare? AIDS Behav 2015;19:1928-1937.

46. Sullivan PS, Khosropour CM, Luisi N, et al.: Bias in online recruitment and retention of racial and ethnic minority men who have sex with men. J Med Internet Res 2011;13:e38.

47. Reisner SL, Conron K, Scout N, et al.: Comparing inperson and online survey respondents in the U.S. National Transgender Discrimination Survey: Implications for transgender health research. LGBT Health 2014;1:98-106.

48. Craig SL, McInroy LB, D'Souza SA, et al.: Influence of information and communication technologies on the resilience and coping of sexual and gender minority youth in the United States and Canada (Project \#Queery): Mixed methods survey. JMIR Res Protoc 2017;6:e189.

49. National Longitudinal Study of Adolescent to Adult Health (Add Health): The National Longitudinal Study of Adolescent to Adult Health: Study design. Available at www.cpc .unc.edu/projects/addhealth/design Accessed January 31, 2019.
50. Centers for Disease Control and Prevention: Youth Risk Behavior Surveillance System (YRBSS): Questionnaires. Available at www.cdc.gov/healthyyouth/data/yrbs/ questionnaires.htm Accessed April 7, 2019.

51. Vaughan R: Oversampling in health surveys: Why, when, and how? Am J Public Health 2017;107:1214-1215.

52. Rasberry CN, Rose I, Kroupa E, et al.: Overcoming challenges in school-wide survey administration. Health Promot Pract 2018;19:110-118.

53. Johnston LG, Sass J, Acaba J, et al.: Ensuring inclusion of adolescent key populations at higher risk of HIV exposure: Recommendations for conducting biological behavioral surveillance surveys. JMIR Public Health Surveill 2017; 3:e40.

54. Heckathorn DD: Snowball versus respondent-driven sampling. Sociol Methodol 2011;41:355-366.

55. Johns MM, Liddon N, Jayne PE, et al.: Systematic mapping of relationship-level protective factors and sexual health outcomes among sexual minority youth: The role of peers, parents, partners, and providers. LGBT Health 2018;5:6-32.

56. Bouris A, Guilamo-Ramos V, Pickard A, et al.: A systematic review of parental influences on the health and wellbeing of lesbian, gay, and bisexual youth: Time for a new public health research and practice agenda. J Prim Prev 2010;31:273-309.

57. D'Augelli AR: Stress and adaptation among families of lesbian, gay, and bisexual youth: Research challenges. J GLBT Fam Stud 2005;1:115-135.

58. Feinstein BA, Thomann M, Coventry R, et al.: Gay and bisexual adolescent boys' perspectives on parentadolescent relationships and parenting practices related to teen sex and dating. Arch Sex Behav 2018;47:18251837.

59. Bouris A, Hill BJ, Fisher K, et al.: Mother-son communication about sex and routine human immunodeficiency virus testing among younger men of color who have sex with men. J Adolesc Health 2015;57:515-522.

60. Thoma BC, Huebner DM: Parental monitoring, parentadolescent communication about sex, and sexual risk among young men who have sex with men. AIDS Behav 2014;18:1604-1614.

61. D'Augelli AR, Grossman AH, Starks MT: Families of gay, lesbian, and bisexual youth. J GLBT Fam Stud 2008;4:95115.

62. Ryan C, Russell ST, Huebner D, et al.: Family acceptance in adolescence and the health of LGBT young adults. J Child Adolesc Psychiatr Nurs 2010;23:205-213.

63. LaSala MC, Siebert CF, Fedor JP, Revere EJ: The role of family interactions in HIV risk for gay and bisexual male youth: A pilot study. J Fam Social Work 2016;19: 113-131.

64. LaSala MC: Condoms and connection: Parents, gay and bisexual youth, and HIV risk. J Marital Fam Ther 2015;41: 451-464.

65. Saewyc EM, Bauer GR, Skay CL, et al.: Measuring sexual orientation in adolescent health surveys: Evaluation of eight school-based surveys. J Adolesc Health 2004;35: 345.e1-e15.

66. Greytak E, Gill A, Conron K, et al.: Identifying transgender and other gender minority respondents on populationbased surveys: Special considerations for adolescents, race/ethnicity, socioeconomic status, and intersex status. In: Best Practices for Asking Questions to Identify 
Transgender and Other Gender Minority Respondents on Population-Based Surveys. Edited by Herman JL. Los Angeles, CA: The Williams Institute, 2014, pp. 29-43.

67. Ainsworth C: Sex redefined. Nature 2015;518:288-291.

68. Bauer GR, Braimoh J, Scheim AI, Dharma C: Transgenderinclusive measures of sex/gender for population surveys: Mixed-methods evaluation and recommendations. PLoS One 2017;12:e0178043.

69. Morandini JS, Blaszczynski A, Dar-Nimrod I: Who adopts queer and pansexual sexual identities? J Sex Res 2017;54: 911-922.

70. Galupo MP, Lomash E, Mitchell RC: "All of my lovers fit into this scale": Sexual minority individuals' responses to two novel measures of sexual orientation. J Homosex 2017;64:145-165.

71. Smalley KB, Warren JC, Barefoot KN: Differences in health risk behaviors across understudied LGBT subgroups. Health Psychol 2016;35:103-114.

72. Kenny DA, DePaulo BM: Do people know how others view them? An empirical and theoretical account. Psychol Bull 1993;114:145-161.

73. World Health Organization: Global Health Estimates. 2016. Available at www.who.int/healthinfo/global_burden_ disease/en Accessed January 31, 2019.

74. National Center for Health Statistics (U.S.): Health, United States, 2016: With chartbook on long-term trends in health. Hyattsville (MD): National Center for Health Statistics (US); 2017 May. Report No.: 2017-1232.

75. Horn SS, Kosciw JG, Russell ST: Special issue introduction: New research on lesbian, gay, bisexual, and transgender youth: Studying lives in context. J Youth Adolesc 2009;38:863-866.

76. Ryan C, Huebner D, Diaz RM, Sanchez J: Family rejection as a predictor of negative health outcomes in white and Latino lesbian, gay, and bisexual young adults. Pediatrics 2009;123:346-352.

77. Marshal MP, Friedman MS, Stall R, Thompson AL: Individual trajectories of substance use in lesbian, gay and bisexual youth and heterosexual youth. Addiction 2009;104: 974-981.

78. Clatts MC, Goldsamt L, Yi H, Gwadz MV: Homelessness and drug abuse among young men who have sex with men in New York City: A preliminary epidemiological trajectory. J Adolesc 2005;28:201-214.

79. Morrison TG, Bishop CJ, Morrison MA, Parker-Taneo K: A psychometric review of measures assessing discrimination against sexual minorities. J Homosex 2016;63:1086-1126.

80. Goldbach JT, Tanner-Smith EE, Bagwell M, Dunlap S: Minority stress and substance use in sexual minority adolescents: A meta-analysis. Prev Sci 2014;15:350-363.

81. Schrager SM, Goldbach JT, Mamey MR: Development of the Sexual Minority Adolescent Stress Inventory. Front Psychol 2018;9:319.

82. Goldbach JT, Schrager SM, Mamey MR: Criterion and divergent validity of the Sexual Minority Adolescent Stress Inventory. Front Psychol 2017;8:2057.

83. Frost DM, McClelland SI, Clark JB, Boylan EA: Phenomenological research methods in the psychological study of sexuality. In: APA Handbook of Sexuality and Psychology Volume 1: Person-Based Approaches. Edited by Tolman DL, Diamond LM. Washington, DC: American Psychological Association, 2014, pp. 121-141.

84. Levine R, Huberman M, Allen J, DuBois P: The measurement of home background indicators: Cognitive laboratory investigations of the responses of fourth and eighth graders to questionnaire items and parental assessments of the invasiveness of these items. Washington, DC: U.S. Department of Education, National Center for Education Statistics, Working Paper No. 2001-19, 2001.

85. Cook C, Heath F, Thompson RL: A meta-analysis of response rates in web- or internet-based surveys. Educ Psychol Meas 2000;60:821-836.

86. Bevans KB, Riley AW, Moon J, Forrest CB: Conceptual and methodological advances in child-reported outcomes measurement. Expert Rev Pharmacoecon Outcomes Res 2010;10:385-396.

87. Austin SB, Conron K, Patel A, Freedner N: Making sense of sexual orientation measures: Findings from a cognitive processing study with adolescents on health survey questions. J LGBT Health Res 2007;3:55-65.

88. Herbst JH, Beeker C, Mathew A, et al.: The effectiveness of individual-, group-, and community-level HIV behavioral risk-reduction interventions for adult men who have sex with men: A systematic review. Am J Prev Med 2007;32:S38-S67.

89. Vergidis PI, Falagas ME: Meta-analyses on behavioral interventions to reduce the risk of transmission of HIV. Infect Dis Clin North Am 2009;23:309-314.

90. Johns MM, Beltran O, Armstrong HL, et al.: Protective factors among transgender and gender variant youth: A systematic review by socioecological level. J Prim Prev 2018;39:263-301.

91. Armstrong HL, Steiner RJ, Jayne PE, Beltran O: Individual-level protective factors for sexual health outcomes among sexual minority youth: A systematic review of the literature. Sex Health 2016;13:311-327.

92. Food and Drug Administration Office of Pediatric Therapeutics, Division of Pediatric and Maternal Health, and Division of Antiviral Products. HIV-1 PrEP drug can be part of strategy to prevent infection in at-risk adolescents. Available at www.aappublications.org/news/2018/06/28/ fdaupdate062818 Accessed April 7, 2019.

93. Allen E, Gordon A, Krakower D, Hsu K: HIV preexposure prophylaxis for adolescents and young adults. Curr Opin Pediatr 2017;29:399-406.

94. Hosek SG, Landovitz RJ, Kapogiannis B, et al.: Safety and feasibility of antiretroviral preexposure prophylaxis for adolescent men who have sex with men aged 15 to 17 years in the United States. JAMA Pediatr 2017;171:1063-1071.

95. Arrington-Sanders R: Human immunodeficiency virus preexposure prophylaxis for adolescent men: How do we ensure health equity for at-risk young men? JAMA Pediatr 2017;171:1041-1042.

96. Marshal MP, Dietz LJ, Friedman MS, et al.: Suicidality and depression disparities between sexual minority and heterosexual youth: A meta-analytic review. J Adolesc Health 2011;49:115-123.

97. Brown $\mathrm{CH}$, Brincks A, Huang S, et al.: Two-year impact of prevention programs on adolescent depression: An integrative data analysis approach. Prev Sci 2018;19(Suppl 1):74-94.

98. Brincks A, Montag S, Howe GW, et al.: Addressing methodologic challenges and minimizing threats to validity in synthesizing findings from individual-level data across longitudinal randomized trials. Prev Sci 2018;19(Suppl 1):60-73.

99. Gibbons RD, Kupfer D, Frank E, et al.: Development of a Computerized Adaptive Test Suicide Scale-The CAT-SS. J Clin Psychiatry 2017;78:1376-1382. 
100. Brown CH, Wang W, Kellam SG, et al.: Methods for testing theory and evaluating impact in randomized field trials: Intent-to-treat analyses for integrating the perspectives of person, place, and time. Drug Alcohol Depend 2008;95 Suppl 1:S74-S104.

101. Kryzan C, Walsh J: The!OutProud!/Oasis Internet Survey of Queer and Questioning Youth, August to October 1997. San Francisco, CA:!OutProud! and Oasis Magazine, 1998. Available at https://files.eric.ed.gov/fulltext/ED419854 .pdf Accessed April 7, 2019.

102. McKenna KY, Bargh JA: Coming out in the age of the Internet: Identity "demarginalization" through virtual group participation. J Pers Soc Psychol 1998;75:681-694.

103. Young SD, Cumberland WG, Lee SJ, et al.: Social networking technologies as an emerging tool for HIV prevention: A cluster randomized trial. Ann Intern Med 2013;159: 318-324.

104. Mustanski B, Lyons T, Garcia SC: Internet use and sexual health of young men who have sex with men: A mixedmethods study. Arch Sex Behav 2011;40:289-300.

105. Mustanski B, Garofalo R, Monahan C, et al.: Feasibility, acceptability, and preliminary efficacy of an online HIV prevention program for diverse young men who have sex with men: The Keep It Up! intervention. AIDS Behav 2013;17:2999-3012.

106. Murray E, White IR, Varagunam M, et al.: Attrition revisited: Adherence and retention in a web-based alcohol trial. J Med Internet Res 2013;15:e162.

107. Bull SS, Levine D, Schmiege S, Santelli J: Recruitment and retention of youth for research using social media: Experiences from the Just/Us study. Vulnerable Child Youth Stud 2013;8:171-181.

108. Lavori PW, Brown CH, Duan N, et al.: Missing data in longitudinal clinical trials part A: Design and conceptual issues. Psychiatr Ann 2008;38:784-792.

109. Miller RL, Forte D, Wilson BD, Greene GJ: Protecting sexual minority youth from research risks: Conflicting perspectives. Am J Community Psychol 2006;37:341348.

110. Mustanski B: Ethical and regulatory issues with conducting sexuality research with LGBT adolescents: A call to action for a scientifically informed approach. Arch Sex Behav 2011;40:673-686.

111. Mustanski B, Fisher CB: HIV rates are increasing in gay/bisexual teens: IRB barriers to research must be resolved to bend the curve. Am J Prev Med 2016;51:249-252.

112. Fisher CB, Mustanski B: Reducing health disparities and enhancing the responsible conduct of research involving LGBT youth. Hastings Cent Rep 2014;44 Suppl 4:S28S31.

113. Snapp SD, Russell ST, Arredondo M, Skiba R: A right to disclose: LGBTQ youth representation in data, science, and policy. Adv Child Dev Behav 2016;50:135-159.

114. D'Augelli AR, Hershberger SL, Pilkington NW: Lesbian, gay, and bisexual youth and their families: Disclosure of sexual orientation and its consequences. Am J Orthopsychiatry 1998;68:361-371; discussion 372-375.

115. Fisher CB, Arbeit MR, Dumont MS, et al.: Self-consent for HIV prevention research involving sexual and gender minority youth: Reducing barriers through evidence-based ethics. J Empir Res Hum Res Ethics 2016;11:3-14.

116. Macapagal K, Coventry R, Arbeit MR, et al.: "I won't out myself just to do a survey": Sexual and gender minority adolescents' perspectives on the risks and benefits of sex research. Arch Sex Behav 2017;46:1393-1409.

117. Mustanski B, Coventry R, Macapagal K, et al.: Sexual and gender minority adolescents' views on HIV research participation and parental permission: A mixed-methods study. Perspect Sex Reprod Health 2017;49:111-121.

118. Liu C, Cox RB Jr, Washburn IJ, et al.: The effects of requiring parental consent for research on adolescents' risk behaviors: A meta-analysis. J Adolesc Health 2017;61: $45-52$.

119. Newcomb ME, Clifford A, Greene GJ, Mustanski B: Parent perspectives about sexual minority adolescent participation in research and requirements of parental permission. J Adolesc Health 2016;59:443-449.

120. Mustanski B, Macapagal K, Thomann M, et al.: Parents' perspectives about adolescent boys' involvement in biomedical HIV prevention research. Arch Sex Behav 2018; 47:1923-1935.

121. University of Illinois at Chicago Center for Clinical and Translational Science: LGBT Target Population Toolkit. Available at http://ccts.uic.edu/content/lgbt Accessed January 31, 2019.

122. National Institutes of Health: Final NIH Policy on the Use of a Single Institutional Review Board for Multi-Site Research. 2016. Available at https://grants.nih.gov/grants/ guide/notice-files/NOT-OD-16-094.html Accessed January 31, 2019.

123. Thompson RS, Rivara FP, Thompson DC, et al.: Identification and management of domestic violence: A randomized trial. Am J Prev Med 2000;19:253-263.

124. Meyer IH, Northridge ME: The Health of Sexual Minorities: Public Health Perspectives on Lesbian, Gay, Bisexual and Transgender Populations. New York, NY: Springer, 2007.

125. Hatzenbuehler ML: Structural stigma: Research evidence and implications for psychological science. Am Psychol 2016;71:742-751.

Address correspondence to:

Sheree M. Schrager, PhD, MS

Department of Research and Sponsored Programs California State University, Northridge 18111 Nordhoff Street

Northridge, CA 91330-8232

E-mail: sheree.schrager@csun.edu 